\title{
NAVARro Floria, Juan G. (Coord.) (2011) Acuerdos y concordatos en- tre la Santa Sede y los países americanos. Buenos Aires: Editorial de la Universidad Católica Argentina, 285 pp.
}

Correspondió a Chile ser el primer país latinoamericano en iniciar relaciones directas con la Santa Sede producida que fue la independencia de los países que habían formado parte de la monarquía española, contactos que dieron origen a la primera misión diplomática enviada por la Santa Sede a los países recientemente independizados, presidida por Giovanni Muzi y en la que venía el entonces joven monseñor Giovanni Maria Mastai Ferreti quien, con el tiempo ocuparía el trono pontificio con el nombre de Pío IX. A partir de ese momento, los contactos entre la Santa Sede y los países latinoamericanos se multiplicaron y desde 1851 empezaron a suscribirse distintos concordatos, siendo el primero de ellos el celebrado con Bolivia el que, aunque no fue ratificado por el Congreso de ese país, sirvió de modelo a los primeros concordatos que se firmaron en ańos sucesivos: Costa Rica (1852), Guatemala I (1852), Haití (1860), Honduras (1861), Nicaragua (1861), Ecuador I (1862), El Salvador (1862), Venezuela (1862), Ecuador II (1881), Guatemala II (1884) y Colombia $(1887,1891)$, sin perjuicio de algunos acuerdos sobre materias específicas y la bula de concesión del derecho de patronato al Presidente del Perú. La mayor parte de ellos, sin embargo, tuvo una vida efímera.

Durante los siglos XX y XXI la práctica concordataria de la Santa Sede con países latinoamericanos no se ha suspendido, a pesar de la mala experiencia decimonónica, y ella ha tenido como resultado la firma de diversos acuerdos cuya vigencia se ha prolongado hasta nuestros días, alguno de los cuales es tan reciente como el que se firmara con Brasil en 2008. A ellos se dedican las páginas de este libro el que, coordinado por el profesor Juan Gregorio Navarro Floria, presenta los concordatos actualmente vigentes en el continente latinoamericano. Originalmente este conjunto de trabajos se publicó en la Revista General de Derecho Canónico y Derecho Eclesiástico del Estado que, en formato digital, se publica en España por la Editorial Iustel.

Después de la presentación del editor y del prólogo de Rafael Navarro-Valls, el primero de los trabajos incluidos es el del mismo editor quien presenta una visión general de los concordatos y acuerdos celebrados entre la Santa Sede y los países americanos, visión en la que se incluye Chile, a pesar de que hasta ahora no ha celebrado concordato alguno; después de unas páginas dedicadas a la "historia de una relación singular", pasa revista a los "distintos casos nacionales" en los que se incluyen Argentina, Bolivia, Brasil, Colombia, Costa Rica, Chile, El Salvador, Ecuador, Guatemala, Haití, Honduras, Nicaragua, Paraguay, Perú, República Dominicana, Venezuela y "los demás países americanos". La Iglesia católica 
ya no busca privilegios sino libertad para llevar adelante su misión en el marco general del derecho de libertad religiosa, libertad que puede verse reforzada para la Iglesia católica por el uso de este instrumento técnico, y también para otras confesiones religiosas, toda vez que al Estado le preocupa evitar la imagen de estar dando privilegios indebidos, todo lo cual entrańa, sin embargo, el riesgo de que "en el altar de la igualdad y la no discriminación se sacrifiquen innecesariamente derechos legítimamente adquiridos, cuando no la libertad religiosa misma”. Es probable, para este autor, que en el futuro las relaciones entre los Estados latinoamericanos y la Santa Sede discurran más por la vía de los acuerdos específicos que por la de concordatos omnicomprensivos, aunque no hay que excluir esta posibilidad.

Seguidamente el profesor Norberto Padilla, que fue Secretario de Culto de la Nación, en Argentina, presenta el acuerdo celebrado entre la República Argentina y la Santa Sede el 10 de octubre de 1966, cuyo texto se reproduce en el apéndice II: después de presentar de manera resumida las regulación dada a la materia religiosa desde la Constitución de 1853, en la que se incorporó el patronato, desarrolla lo que denomina "el primer paso", que fue la firma del acuerdo sobre la atención religiosa de las Fuerzas Armadas, el 28 de junio de 1957, primer paso que sería seguido por la firma del acuerdo de 1966, apenas acabado el Concilio Vaticano II, cuyo contenido ofrece, ilustrándolo con jurisprudencia del Estado, haciendo finalmente una balance y mostrando las perspectivas que a futuro ofrece este acuerdo que, en siete artículos, reconoce y garantiza a la Iglesia el libre y pleno ejercicio de su poder espiritual, por lo cual podrá erigir nuevas circunscripciones eclesiásticas o cambiar las existentes, debiendo la Santa Sede comunicar confidencialmente al gobierno sus intenciones, comunicación que igualmente debía hacer antes de proceder al nombramiento de arzobispos y obispos residenciales y prelados o coadjutores con derecho a sucesión. Además se reconoce el derecho de la Santa Sede de publicar en Argentina las disposiciones relativas al gobierno de la Iglesia y de mantener comunicación con los obispos y fieles, facultad de la que también gozan los obispos, quienes pueden llamar al país a las órdenes y congregaciones masculinas o femeninas que consideren útiles.

A los acuerdos entre la Santa Sede y Brasil se dedica el siguiente trabajo, del que es autor Evaldo Xavier Gomes. La separación entre la Iglesia y el Estado coincide en Brasil con el nacimiento de la República al promulgarse la Constitución de 1891, no obstante lo cual tres son los acuerdos actualmente vigentes entre la Santa Sede y la República del Brasil: los acuerdos sobre la correspondencia de carácter diplomático (1935), sobre la asistencia religiosa a las Fuerzas Armadas (1989) y el relativo al estatuto jurídico de la Iglesia Católica en Brasil (2008). Este último, aun cuando se denomina "acuerdo", entre otras razones porque es un término más moderno y está en mejor sintonía con el lenguaje de laicidad, comprende 
una variedad de materias propias de un concordato, todas las cuales son debidamente analizadas en estas páginas, en concreto: el reconocimiento de la personalidad jurídica de la Iglesia católica, la enseñanza de la religión católica en las escuelas públicas, la extensión a la Iglesia católica de los beneficios legales que el derecho brasileńo concede a las entidades filantrópicas, la regulación de los efectos civiles del matrimonio canónico y de las sentencias eclesiásticas en materia matrimonial, la adscripción de espacios para fines religiosos en el ámbito urbanístico, el derecho a la asistencia espiritual en establecimientos de internamiento colectivo, la exclusión del vínculo laboral de los ministros ordenados, el derecho de la Iglesia de desplegar su misión apostólica y el ejercicio público de sus actividades, además de otros derechos como que ninguna circunscripción eclesiástica brasileña dependerá de un obispo cuya sede episcopal se encuentre fuera del territorio nacional, o que el patrimonio histórico, artístico y cultural de la Iglesia católica es parte del patrimonio cultural brasileño.

Vicente Prieto, profesor de derecho eclesiástico del Estado en la Universidad de la Sabana, es el autor de las páginas dedicadas a los acuerdos vigentes entre Colombia y la Santa Sede. El concordato actualmente en vigor fue suscrito en Bogotá el 12 de julio de 1973, si bien las relaciones concordatarias tiene antecedentes decimonónicos que el autor ofrece en una sucinta relación histórica. Después de una visión de conjunto del concordato, se analiza la nueva Constitución de 1991 y la reforma concordataria de 1992 en lo referido al matrimonio, necesaria después de la introducción del divorcio. El concordato, sin embargo, pese a su vigencia, ha sufrido diversos embates después que la Corte Constitucional asumió la competencia para resolver sobre la constitucionalidad de un tratado internacional ratificado, en virtud de lo cual declaró que diversos artículos del concordato no eran conformes con la Constitución. El estado actual del concordato es que hay normas declaradas inconstitucionales y otras conformes con la Constitución, todas las cuales son analizadas en sus pormenores. No obstante esto, como lo pone de relieve el autor, en una situación sociológica de pluralidad religiosa, el sistema concordatario, que originalmente ha inspirado en Colombia el modelo de relaciones entre el Estado y la Iglesia, después de 1991 ha inspirado las relaciones del Estado con otras confesiones religiosas, pues muchas de las disposiciones concordatarias se han convertido en normas generales o se han extendido sin dificultad a las demás confesiones. Con todo, desde el punto de vista del derecho eclesiástico, la situación actual del concordato resulta precaria desde el punto de vista de la claridad y de la seguridad jurídicas, por lo que hay consenso en que el camino hacia una solución jurídicamente clara es reiniciar las conversaciones entre las partes para la suscripción de un nuevo concordato o la revisión del actual, lo que permitiría plantear materias no previstas en el texto vigente y que han cobrado relevancia en los 
últimos años como la objeción de conciencia, el ideario de centros educativos y asistenciales, símbolos religiosos en lugares públicos, etc.

Los acuerdos entre la Santa Sede y Ecuador son presentados por Jaime Baquero, país que tiene una historia concordataria desde el siglo XIX, historia que no fue ajena a las vicisitudes de otros concordatos del continente, las que son expuestas en las primeras páginas de este trabajo que muestra, después, las normas en actual vigencia, en concreto, el modus vivendi de 1937 que, en diez artículos, garantiza principalmente la libertad de la Iglesia para llevar adelante las actividades que le son propias y su derecho a fundar planteles educativos en todos los niveles. Un segundo acuerdo vigente es el relativo a la asistencia religiosa de las Fuerzas Armadas y la Policía Nacional de 1978. El modus vivendi, cuya vigencia se ha extendido por más de 70 años, se conjuga en la actualidad con el Reglamento de Cultos vigente desde el ańo 2000, lo que permite al autor finalizar su presentación con algunas consideraciones sobre el reconocimiento de la personalidad jurídica de las entidades religiosas, y la educación, con especial referencia a la educación religiosa, a los convenios del Estado con las órdenes religiosas y a ley de libertad educativa para las familias del Ecuador y su jurisprudencia.

El último de los trabajos incluidos en este libros es de Juan José Ruda Santolaria que muestra el acuerdo entre la Santa Sede y la República del Perú, país que en el siglo XIX obtuvo de la Santa Sede, mediante la bula Praeclara de Pío IX (1875), "el derecho de patronato del que gozaban, por gracia de la Santa Sede, los reyes católicos de España”, rompiendo una línea de actuación que había iniciado la Santa Sede con los concordatos celebrados ańos antes con algunos países latinoamericanos en los que, si bien se concedía el derecho de patronato, era este entendido como un privilegio que otorgaba la Santa Sede desprendido de toda relación con el patronato español y sin aceptar que el mismo era un derecho inherente a la soberanía de los Estados. Excepción que de inmediato sería remediada con los sucesivos concordatos (Guatemala II y Colombia) que darían paso hacia el derecho de prenotificación. El acuerdo en actual vigencia fue celebrado el 19 de julio de 1980 el que, en un solo texto, aborda la mayoría de los asuntos de importancia relacionados con el estatuto de la Iglesia católica en el Perú o de interés común para ella y para el Estado, todas las cuales son expuestas en estas páginas, poniendo de relieve el autor aquellas que no están contempladas en su articulado como la de los efectos civiles del matrimonio canónico o la protección de los bienes culturales de propiedad de la Iglesia.

Dos apéndices completan este libro: un índice cronológico de los acuerdos y concordatos firmados entre la Santa Sede y Estados latinoamericanos (apéndice 1) y algunos acuerdos y concordatos vigentes entre la Santa Sede y Estados latinoamericanos, en concreto Argentina, Bolivia -convenios sobre las misiones y sobre asistencia religiosa a las Fuerzas Ar- 
madas y Fuerzas de la policía nacional- Brasil -acuerdos sobre asistencia religiosa a las Fuerzas Armadas y sobre el estatuto jurídico de la Iglesia católica en Brasil- Colombia, Paraguay, Perú, República Dominicana, Venezuela (apéndice 2).

Pese a las no siempre fáciles relaciones entre la Iglesia y el Estado en América Latina, especialmente durante el siglo XIX, es un hecho patente que no es escaso el número de países latinoamericanos que tiene acuerdos con la Santa Sede, alguno relativamente recientes, como el de Perú de 1980 y otro más reciente aún, como el de Brasil de 2009, los cuales optaron por la forma de un concordato o texto único, pues, aunque el de Brasil recibe el nombre de acuerdo, regula la mayor parte de las materias en las que tienen interés el Estado y la Iglesia. Esto, aunque ambos han sido celebrados después que entre la Santa Sede y España, país que resulta más cercano a nosotros, se haya optado por la modalidad de acuerdos parciales. Se trata de una muestra de la vitalidad que exhibe en la actualidad este viejo instrumento lo que permite pensar en la posibilidad de un acuerdo de dicha naturaleza con nuestro país. Intentos para llegar a un tal acuerdo los ha habido en el siglo XIX y en el siglo XX, llevados adelante tanto por los gobiernos de Chile en aquel y por la Santa Sede en este, según recientemente se ha conocido, pero ninguno de dichos esfuerzos ha dado resultados hasta ahora. Pienso, pues, que ha llegado el momento de que el mundo académico, especialmente de las universidades católicas, empiece a reflexionar sobre la posibilidad concreta de celebrar uno o varios acuerdos con la Santa Sede, cuya modalidad y contenido habrá que ir perfilando de manera que cuando se presente la oportunidad política de hacerlo, la serena reflexión académica precedente facilite la obra. Las páginas de este libro son un precioso elemento de información que permitirá ir definiendo temas y modalidades de ejecución, teniendo siempre en cuenta las particularidades específicas con las que el mismo y único mensaje evangélico ha sido predicado en estas tierras en cumplimiento que aquel mandato que diera Cristo de predicar el Evangelio a todas las naciones.

\section{Carlos Salinas Araneda*}

\footnotetext{
* Doctor en Derecho por la Universidad Complutense de Madrid (España) y Doctor en Derecho Canónico por la Universidad Pontificia Santo Tomás in Urbe (Angelicum) de Roma (Italia). Profesor titular de Historia del Derecho y de Derecho Canónico, Facultad de Derecho de la Pontificia Universidad Católica de Valparaíso (CHILE). Correo electrónico: csalinas@ucv.cl
} 